\title{
Imigração, relações familiares e atividades econômicas no Brasil Meridional: formas de ingresso e mobilidade social de três açorianos em áreas litorâneas da Capitania de São Paulo (Morretes e Paranaguá, 1780-1820)
}

André Luiz Moscaleski Cavazzani* Sandro Aramis Richter Gomes**

Resumo: O presente estudo comporta uma investigação sobre os processos de enraizamento e mobilidade social de três imigrantes açorianos em duas áreas litorâneas da Capitania de São Paulo - a povoação de Morretes e a vila de Paranaguá - entre os anos de 1780 e 1820. Em um sentido amplo, a finalidade capital deste artigo consiste em produzir um conhecimento respeitante à natureza das oportunidades sociais e econômicas auferidas por açorianos que participaram do fluxo migratório para áreas litorâneas do Brasil Meridional na segunda metade do século XVIII. Nesse quadro, o argumento central desta investigação afirma que, no contexto dos anos 1780, a imigração de açorianos para o extremo sul da Capitania de São Paulo era, por vezes, um projeto familiar. Desse modo, é salientado que existiam formas de solidariedade entre membros de distintas gerações entre imigrantes açorianos e portugueses. Nesse quadro, faz-se o emprego de duas fontes. Inicialmente, são estudados processos de dispensas matrimoniais, os quais contêm informações sobre os primórdios do

Doutor em História Social pela Universidade de São Paulo. Professor do Centro Universitário Internacional Uninter. E-mail: andrexcava@gmail.com Doutor em História pela Universidade Federal do Paraná. E-mail: argomes8@ gmail.com

Anos 90, Porto Alegre, v. 24, n. 46, p. 211-238, dez. 2017 
Imigração, relações familiares e atividades econômicas no Brasil...

enraizamento social dos três açorianos aqui arrolados. São estudadas, também, duas listas nominativas de habitantes, a qual permite conhecer o destino desses imigrantes no início do século XIX.

Palavras-chave: Açorianos. Brasil Meridional. Elites locais. Imigração.

\section{Introdução}

Neste artigo é desenvolvida, por meio de estudos de casos, uma abordagem sobre os processos de inserção e mobilidade social de açorianos que se estabeleceram em áreas do litoral sul da Capitania de São Paulo na segunda metade do século XVIII. A finalidade precípua deste estudo é a produção de um entendimento sobre a natureza das oportunidades econômicas auferidas por imigrantes lusófonos que se estabeleceram em municípios litorâneos do Brasil Meridional na mencionada época. Este artigo enquadra-se, portanto, em uma vertente de análise destinada a reconhecer os aspectos da diferenciação social interna aos membros de comunidades étnicas formadas no Sul do Brasil no contexto das décadas finais da época colonial.

Desse modo, é realizada neste estudo a sustentação de dois argumentos capitais. Primeiro, afirma-se que o estabelecimento de açorianos em Morretes e Paranaguá, na segunda metade do século XVIII, assumiu, por vezes, o aspecto de um projeto familiar. Uma vez estabelecidos na sociedade receptora, os ilhéus logravam estabelecer conexões econômicas e familiares em vilas e freguesias adjacentes àquelas localidades. A ampliação dessas conexões garantia tanto a integração na vida comercial quanto nas atividades políticas e administrativas de localidades tais como a vila de Paranaguá. A atenção aos percursos dos irmãos Ferreira de Oliveira permite corroborar estas assertivas.

Segundo, compete demonstrar que os açorianos, ao se fixarem na referida localidade, não se enquadravam, em todos os casos, na condição de comerciantes autônomos. De fato, o envolvimento na lide mercantil fora característico de uma parcela desses imigrantes. Porém, havia ocasiões nas quais a atuação na vida agrária era o destino dos insulanos. Cabe evidenciar, ainda, que a formação de 
uma escravaria consta como um indicador do poder econômico e da consistência do enraizamento dos açorianos na vida econômica da sociedade receptora.

Comumente, os estudos sobre comunidades étnicas no Brasil Meridional e, em particular, no território do atual Paraná dedicaram especial atenção ao comportamento demográfico dos imigrantes. $\mathrm{O}$ estudo sobre as mudanças em padrões de natalidade e nupcialidade constam nesses estudos como elementos centrais da identificação do processo de incorporação dos imigrantes a uma sociedade receptora.

Desenvolvidas, notadamente, entre as décadas de 1970 e 1980, as análises acerca nas mudanças nos padrões demográficos de distintas comunidades étnicas ao longo do século XIX não conferiram ênfase aos aspectos das desigualdades sociais e econômicas inerentes aos compatrícios de distintas nacionalidades estabelecidos em áreas sulinas (BALHANA, 1978; NADALIN, 1978; RANZI, 1983; QUEIROZ, 1992; WACHOWICZ, 1974). Remanescem, pois, escassos os esforços destinados à identificação das formas de hierarquização de comunidades étnicas no Brasil Meridional ao tempo da colônia. Preponderam, pois, estudos atinentes à organização e estratificação dessas comunidades ao longo dos séculos XIX e XX. (BLUME; WITT, 2014; ROCHE, 1969; SAYFERTH, 1999; STORMOWSKI, 2014; VENDRAME, 2016). Mais precisamente, esses esforços propiciaram um conhecimento sobre aspectos da acomodação de imigrantes alemães na então Província do Rio Grande do Sul.

Assim, há predomínio de estudos sobre imigração que se dedicam ao estudo da época em que o Governo Imperial principiou a estimular o estabelecimento de imigrantes europeus no Brasil. A consecução do presente estudo, por sua vez, propicia uma compreensão das condições de ingresso e mobilidade social de açorianos no extremo sul do litoral da Capitania de São Paulo. Referente a um contexto anterior à existência de estímulos do Estado para a fixação de imigrantes, esta investigação dedica ênfase às características da recepção e do movimento de açorianos em pequenas vilas litorâneas.

Presentemente, os estudos sobre grupos étnicos atêm-se sobre as características e fatores da unidade interna às comunidades de imigrantes constituídas na região Sul (BIDEAU; NADALIN, 2011; HELFENSTEIN, 2014; SCARPIM, 2010). Verifica-se, pois, que se 
Imigração, relações familiares e atividades econômicas no Brasil...

mantém central em tais análises o intuito de reconhecer a natureza da vida comunitária dos imigrantes na sociedade receptora. Para tanto, são estudados aspectos da experiência religiosa e dos modos de estabelecimentos de conexões familiares. Tais estudos são, em última análise, tributários das analises do sociólogo alemão Ferdinand Tönnies a respeito da natureza e formas de vínculos comunitários (TÖNNIES, 1995).

De outra parte, trata-se de salientar que, a partir dos anos 2000, houve a produção de estudos orientados pelo objetivo de investigar as formas de enraizamento social de açorianos e as suas estratégias de constituição de vínculos familiares no Rio Grande do Sul ao longo dos séculos XVIII e XIX (HAMEISTER, 2006; MARQUES, 2012; SCOTT, 2014). Por meio da reconstituição de trajetórias individuais, tais estudos evidenciam a operacionalidade do estabelecimento de vínculos familiares no âmbito dos processos de inserção e mobilidade social.

Respeitante à vida econômica e social do litoral paranaense, a historiografia tem dedicado atenção à composição das fortunas de negociantes portugueses, aos modos de dominação e dependência social que existiram entre imigrantes portugueses ali radicados e ao funcionamento da vida mercantil no século XIX (CAVAZZANI, 2013; LEANDRO, 2003).

Mantém-se, portanto, em estágio incipiente a compreensão sobre as distâncias sociais entre membros da comunidade étnica portuguesa formada em Paranaguá e nos municípios adjacentes a partir da segunda metade do século XVIII. Por conseguinte, há uma restrita compreensão sobre os fatores sociais e econômicos que criavam oportunidades ou impunham limites ao enraizamento e mobilidade de indivíduos provenientes do Arquipélago dos Açores e do Reino de Portugal naquela região. A análise de trajetos individuais, no interior dos estudos sobre a imigração no território do atual Paraná, não auferiu expressivo desenvolvimento (CARVALHO NETTO, 1991; MACHADO, 1998).

Dessa forma, a execução do presente artigo tem por finalidade evidenciar, por meio de estudos de caso, das estratégias comuns a imigrantes açorianos para a fixação em Morretes e Paranaguá. Ao mesmo tempo, compete evidenciar a existência de um processo por 
meio do qual os compatrícios pertencentes a uma mesma geração diferenciaram-se do ponto de vista do poder econômico.

$\mathrm{O}$ presente estudo é desenvolvido em três etapas. Na primeira etapa do artigo é analisado o percurso do açoriano João Ferreira de Oliveira. Nesse estágio, demonstra-se que havia ocasiões nas quais, no litoral do atual Paraná, na segunda metade do século XVIII, a migração para o Brasil consistia em um projeto familiar. Mais especificamente, não era incomum que a recepção de um imigrante fosse realizada por parente que já se fixara em uma sociedade sulina.

A partir dessa etapa da investigação, compete sustentar o argumento de que a imigração não era uma iniciativa destituída de planejamento. Uma das formas de planejamento era auferir o respaldo de compatrícios radicados na sociedade receptora para executar o projeto migratório.

$\mathrm{O}$ oferecimento, a imigrantes recém-chegados, de apoio de compatrícios para o estabelecimento no litoral sul da Capitania de São Paulo foi uma prática realizada por membros da família Ferreira de Oliveira entre as décadas finais do século XVIII e o início do século XIX. Dessa forma, o estudo do caso de João Ferreira de Oliveira permite destacar a reiteração, no mencionado recorte temporal, de formas de alianças sociais entre distintas gerações de imigrantes oriundos dos Açores e do Reino de Portugal.

A segunda etapa do artigo consiste na reconstituição do percurso de Francisco Ferreira de Oliveira, irmão do citado João Ferreira de Oliveira, no município de Paranaguá. Nesse âmbito, são evidenciadas as características e limites das oportunidades sociais auferidas por imigrantes lusófonos e, em particular, os açorianos, na vida comercial e administrativa daquele município. Uma das oportunidades era torna-se comerciante autônomo. Tal condição, por sua vez, habilitava o imigrante a acolher e treinar na vida mercantil os compatriotas que se estabeleceram em Paranaguá nos anos finais do século XVIIII.

Demonstra-se, assim, que a faculdade de conferir esse treinamento criava um vínculo de dependência e dominação entre o imigrante e o seu compatriota, no contexto do aludido município. A condição de ser treinado na vida mercantil por um compatriota era fator decisivo para viabilizar o ingresso do recém-chegado nos esquemas matrimoniais do litoral sul paulista, no limiar do século XIX. 
Imigração, relações familiares e atividades econômicas no Brasil...

Outras oportunidades angariadas por açorianos em Morretes e Paranaguá eram o ingresso na Companhia de Ordenanças e o exercício de cargos administrativos municipais. Desse modo, nesse estágio do artigo é evidenciado que um dos indicadores da mobilidade social de Francisco Ferreira de Oliveira era participar de processos de tomada de decisão a respeito de pleitos econômicos e políticos da elite social do litoral do atual Estado do Paraná. O estudo do percurso desse indivíduo, portanto, permite reconhecer as formas de prestígio social que imigrantes lusófonos buscaram angariar no decorrer do seu enraizamento na sociedade receptora.

Uma das estratégias para a conquista de tal prestígio era a atuação na vida política e administrativa municipal. No aludido contexto, não era incomum que imigrantes estabelecidos em praças mercantis maiores, a exemplo da cidade do Rio de Janeiro, almejassem exercer cargos administrativos (BRAGA, 2014). Cabe destacar, ainda, que o emprego de tais estratégias, no contexto da vila de Paranaguá setecentista, era mais difundido entre portugueses do que entre os açorianos.

$\mathrm{Na}$ terceira etapa do artigo é estudado o percurso do açoriano José Soares, o qual se dedicou à vida agrícola. A execução deste estágio da análise permite um conhecimento sobre a condição social e econômica de imigrantes que não se radicaram nas pequenas áreas urbanas de vilas e freguesias do litoral sul paulista. A análise do envolvimento de portugueses na vida comercial de municípios de capitanias como o Rio de Janeiro e São Paulo é central em estudos acerca da vida econômica do período colonial (GORENSTEIN; MARTINHO, 1993; BORREGO, 2010).

Assim, a consecução desta derradeira etapa do artigo apresenta evidências a respeito das bases do poder econômico de um imigrante que não se integrou à elite mercantil da vila de Paranaguá. Nesse particular, argumenta-se que a capacidade de formar uma escravaria cujo contingente era superior à média de componentes de escravarias do município é um indicador da consistência do enraizamento do mencionado açoriano na sociedade receptora.

Neste artigo são empregadas como fontes as dispensas matrimoniais dos referidos imigrantes açorianos, as Listas Nominativas 
de Habitantes de Paranaguá e Antonina do ano de 1808, e os textos memorialísticos do imigrante português Antônio Vieira dos Santos (1784-1854).

As dispensas matrimoniais eram processos por meio dos quais os imigrantes que pretendiam contrair núpcias, no contexto do Brasil colonial, comprovavam que não possuíam qualquer embaraço para se casar na sociedade receptora. Ou seja, eles comprovavam que não haviam prometido contrair matrimônio com outra mulher e que jamais foram casados. Comumente, os processos de dispensa matrimonial contavam com a participação de três testemunhas, as quais corroboravam as informações fornecidas pelos nubentes. Esse processo era conduzido por sacerdotes da Igreja Católica (GOLDSCHMIDT, 2004).

Em suma, o estudo das dispensas é operacional para evidenciar aspectos do processo de enraizamento social dos açorianos aqui arrolados, visto que tais processos contêm informações a respeito dos primeiros contatos sociais e atividades econômicas desenvolvidas pelos jovens imigrantes. Ao mesmo tempo, a atenção aos perfis sociais das testemunhas desses processos permite reconhecer aspectos do círculo de relações sociais dos imigrantes nos primórdios de sua inserção no litoral sul da Capitania de São Paulo. As dispensas matrimoniais aqui utilizadas estão sob a guarda do Arquivo Metropolitano Dom Leopoldo e Silva, da Mitra Diocesana de São Paulo, a qual está situada na capital paulista. ${ }^{1}$

As listas nominativas, por seu turno, possibilitam reconhecer aspectos da mobilidade social dos mencionados imigrantes duas décadas após contraírem núpcias na sociedade receptora. Mais precisamente, as listas comportam informações a respeito do pertencimento dos aludidos açorianos na Companhia de Ordenanças e na vida econômica do município de Paranaguá e da povoação de Morretes, que estava, em 1808, sob a jurisdição da vila de Antonina.

Os textos memorialísticos de Vieira dos Santos, por fim, permitem o conhecimento sobre atividades econômicas e ligações familiares dos mencionados irmãos Ferreira de Oliveira. Vieira dos Santos fora caixeiro de Francisco Ferreira de Oliveira e contraíra núpcias com uma filha de João Ferreira de Oliveira, Maria. 
Imigração, relações familiares e atividades econômicas no Brasil...

Reunidos sob o título de Breve resumo das memórias mais notáveis acontecidas desde 1797 até 1827, esse conjunto de textos de reminiscências favorece o entendimento acerca da natureza das interações e formas de solidariedade social entre membros de distintas gerações de imigrante reinóis e açorianos estabelecidos em Morretes ( e Paranaguá entre o fim do século XVIII e o início do século XIX. ${ }^{2}$

\section{Planejamento, absorção social e interação entre gerações de imigrantes na povoação de Morretes: o caso de João Ferreira de Oliveira}

O estudo sobre o ingresso e mobilidade de João Ferreira de Oliveira no litoral do extremo sul da Capitania de São Paulo permite a sustentação de dois argumentos. Primeiro, cumpre demonstrar que a obtenção de acolhida por um compatrício na sociedade receptora era de importância fulcral para a fixação do imigrante. Em determinadas ocasiões, eram os familiares do imigrante que lhe ofereciam tal acolhida. Portanto, verifica-se que a povoação de Morretes e a vila de Paranaguá, dos anos finais do século XVIII ao princípio do século XIX, foram espaços do ingresso de famílias de imigrantes, tais como os Ferreira de Oliveira.

Segundo, argumenta-se que atingir a condição de comerciante autônomo era um dos limites das oportunidades sociais auferidas por imigrantes reinóis e açorianos no litoral do atual Paraná, no fim da época colonial. Nesse quadro, a comunidade étnica de imigrantes de origem portuguesa, naquela região, era marcada pela interação entre distintas gerações de comerciantes varejistas. Demonstra-se, assim, que os imigrantes recém-chegados enxergavam no vínculo com parentelas de reinóis e açorianos uma oportunidade para ampliarem de modo célere as suas conexões familiares e econômicas.

O processo de dispensa matrimonial de João Ferreira de Oliveira foi iniciado no dia 19 de setembro de 1783 pelo vigário interino de Paranaguá, Joaquim da Costa Resende. Nessa oportunidade, João Ferreira informou que era natural da Ilha do Pico, que está situada no Arquipélago dos Açores. Ele buscava, então, o atestado de que 
estava habilitado a casar-se com Ana Gonçalves Cordeiro, natural da vila de Paranaguá.

$\mathrm{Na}$ época da abertura de seu processo de dispensa matrimonial, o citado imigrante estava na idade de 19 anos e residia há três anos na povoação de Morretes, que pertencia à jurisdição do município de Paranaguá. Desse modo, a fixação desse açoriano no Brasil ocorreu por volta do ano de 1780 (Processo de Dispensa Matrimonial de João Ferreira de Oliveira, 1783, p. $1^{3}$ ).

O depoente afirmou que, quando de sua partida dos Açores, o seu destino era a povoação de Morretes. Na vila de Paranaguá, no início dos anos 1780, estava radicado um de seus irmãos, Antônio Ferreira de Oliveira, que detinha a patente de Tenente da Companhia de Ordenanças. Tal informação consiste em evidência de que, no âmbito do litoral sul paulista, na segunda metade do século XVIII, a migração de açorianos revestia-se de um caráter familiar. Ou seja, havia casos em que imigrantes recém-chegados eram acolhidos por parentes. Essa acolhida era a etapa inicial do estabelecimento de conexões sociais e familiares com locais e também com outros adventícios.

De fato, há tempos a historiografia tem enfatizado que, ao longo do século XVIII, nas capitanias do Rio Grande do Sul e de Santa Catarina houve recorrentes casos de insulanos que emigraram do Arquipélago dos Açores em companhia de familiares. Nesse âmbito, o projeto migratório era um evento que mobilizava distintos membros de uma parentela, inclusive indivíduos que já haviam constituído família nos Açores (PIAZZA, 1997; QUEIROZ, 1987).

As informações contidas nas fontes aqui selecionadas permitem evidenciar, por seu turno, a prática da recepção de açorianos por parentes no litoral sul paulista. Dentre os imigrantes recepcionados, estavam tanto menores de idade que buscavam se iniciar nos misteres do comércio quanto adultos que não lograram decisivas oportunidades sociais e econômicas nos Açores. Os irmãos João e Francisco Ferreira de Oliveira pertencem à primeira categoria de imigrantes.

João Ferreira, portanto, transferiu-se para uma região na qual um irmão já havia alcançado consistente enraizamento. Essa consistência é aferida pelo fato de que estava em posição superior na Companhia de Milícias de Paranaguá. Dessa forma, há de se 
Imigração, relações familiares e atividades econômicas no Brasil...

considerar a hipótese que o estabelecimento de João Ferreira em Morretes e seu ingresso na vida comercial derivavam da orientação de um irmão que estava ambientado com o funcionamento da vida econômica e administrativa de Paranaguá.

Conforme evidenciado na seção seguinte deste artigo, a inserção de Francisco Ferreira de Oliveira na vila de Paranaguá, nos anos 1780, consiste em evidência de que havia membros de parentelas açorianas que, juntos, se dedicavam a executar uma análoga estratégia de enraizamento social. No caso da família Ferreira de Oliveira, a convergência das trajetórias de seus membros radicados no litoral do atual Paraná consistiu na integração na vida mercantil, pois se tornaram comerciantes autônomos. Em resumo, a fixação em pequenos núcleos urbanos existentes naquela região foi aspecto comum aos percursos sociais de três integrantes na família Ferreira de Oliveira no contexto das décadas finais do século XVIII.

De um lado, esse processo de dispensa matrimonial permite salientar a existência de uma forma de solidariedade interna a uma família imigrante. $\mathrm{O}$ acolhimento de um imigrante por outro familiar era o estágio inicial do treinamento do recém-chegado nas lides do comércio varejista. Tal acolhimento era, ainda, a etapa prévia da ampliação dos vínculos sociais do jovem açoriano no litoral sul paulista.

O estudo da dispensa matrimonial de João Ferreira possibilita salientar que, no início de sua inserção no extremo sul do litoral paulista, os seus principais interlocutores eram imigrantes oriundos dos Açores. Tal informação consiste em uma evidência de que compatriotas marcados por semelhante condição social permaneciam próximos na sociedade receptora. Para atestar esta assertiva, compete identificar os perfis sociais das testemunhas arroladas no processo de dispensa matrimonial de João Ferreira.

A análise dos perfis dessas testemunhas permite a elaboração de duas afirmações. Primeiro, nos primórdios de sua inserção no litoral sul paulista, João Ferreira de Oliveira mantinha conexões com açorianos dedicados tanto ao comércio varejista quanto ao trabalho marítimo. Segundo, é imperioso reconhecer a relação entre o exercício de uma ocupação profissional e as condições de envolvimento nos esquemas matrimoniais da vila de Paranaguá, nos anos 1780. 
Nesse âmbito, o exercício da atividade de comerciante varejista permitia uma inserção mais consistente do imigrante açoriano naquela localidade. Por conseguinte, ele, o imigrante, detinha maiores condições de ingressar de forma célere no mercado matrimonial João Ferreira, por exemplo, casou-se após três anos de sua chegada à povoação de Morretes. Por outro lado, o exercício da ocupação de marujo impunha um tempo maior de espera para que houvesse o estabelecimento de vínculos sociais mais sólidos do imigrante na sociedade receptora. Portanto, existia a tendência de os marujos açorianos permanecerem mais tempo na condição de celibatários.

A primeira testemunha do processo de dispensa matrimonial de João Ferreira era o seu irmão Antônio Ferreira de Oliveira. Em 1783, ele estava na idade de 31 anos, era casado e proprietário de negócio de fazenda seca. Ou seja, nessa época Antônio Ferreira atuava como comerciante varejista em Paranaguá (Processo de Dispensa Matrimonial de João Ferreira de Oliveira, 1783, p. 3).

Cumpre salientar que o núcleo urbano de Morretes dista cerca de trinta quilômetros do núcleo urbano de Paranaguá. Por meio do estudo das trajetórias dos irmãos Ferreira de Oliveira, nota-se que o estabelecimento de parentes em uma mesma jurisdição - o município de Paranaguá, por exemplo - não implicava, em todos os casos, uma situação na qual esses indivíduos viveriam fisicamente próximos.

Porém, a distância física não arrefecia as formas de solidariedade entre membros de uma família imigrante. Desse modo, cabe destacar que Antônio Ferreira foi o fiador do débito que João Ferreira realizou junto à Igreja Católica para iniciar o seu processo de dispensa matrimonial (Processo de Dispensa Matrimonial de João Ferreira de Oliveira, 1783, p. 3).

Nesse contexto, os elementos fundamentais da consolidação do enraizamento social do açoriano Antônio Ferreira de Oliveira em Morretes eram a admissão ao mercado matrimonial da localidade e a ascensão em postos da Companhia de Ordenanças de Paranaguá. Conforme salientado neste artigo, esse imigrante detinha, em 1783, a patente de Tenente.

A segunda testemunha do processo de dispensa era João Francisco de Remédio, natural da Ilha de São Miguel, situada nos Açores. $\mathrm{Na}$ ocasião, essa testemunha afirmou que vivia de andar embarcado, 
Imigração, relações familiares e atividades econômicas no Brasil...

estava na idade de 26 anos e era solteiro. Remédio afirmou que estabeleceu seus primeiros contatos com João Ferreira quando este estava na cidade do Rio de Janeiro e se dirigia para o litoral sul paulista. Portanto, o depoimento de Remédio permite asseverar que este marujo fixara-se no Brasil anteriormente a João Ferreira (Processo de Dispensa Matrimonial de João Ferreira de Oliveira, 1783, p. 4).

Todavia, a antiguidade de seu pertencimento à sociedade receptora não lhe permitira, no início dos anos 1780, ser absorvido ao mercado matrimonial existente na vila de Paranaguá. Em síntese, verifica-se que uma diferença capital entre os açorianos radicados no extremo sul do litoral paulista, nas décadas finais do século XVIII, era decorrente da maior ou menor capacidade de constituição de vínculos familiares com membros da sociedade receptora ou mesmo com seus compatrícios ali fixados. Nesse âmbito, a ocupação profissional desempenhada pelo imigrante interferia de modo decisivo para viabilizar ou impor restrições à construção dos aludidos vínculos.

A terceira testemunha desse processo de dispensa era Manuel Gonçalves Machado, natural da Ilha do Pico. Na ocasião de seu depoimento, esse açoriano estava na idade de 24 anos, era casado e atuava como comerciante varejista (Processo de Dispensa Matrimonial de João Ferreira de Oliveira, 1783, p. 4).

Nota-se, portanto, que Manuel Machado e João Ferreira, ambos comerciantes, conseguiram estabelecer vínculos familiares na sociedade receptora de forma mais célere de que outro compatriota, o citado marinheiro João Fernandes Remédio. Essa informação permite reafirmar a conexão entre a natureza da ocupação profissional e as condições de enraizamento e formação de conexões sociais pelos imigrantes açorianos no litoral sul paulista do fim do século XVIII.

Por outro lado, trata-se de salientar que existiam precisos limites para a mobilidade social de açorianos que se dedicaram ao comércio varejista na área litorânea do atual Paraná, nos anos finais do século XVIII e no princípio do século XIX. A esse respeito, compete empregar informações da Lista Nominativa de Paranaguá referente ao ano de 1808 .

Nessa época, Manuel Machado conservava-se na condição de pequeno comerciante. Mais precisamente, ele era referido naquele 
documento como chefe de domicílio que vivia de sua venda. Ele possuía apenas um escravo, o negro Caetano, de 11 anos, e não há menção há filhos e agregados em sua residência (DEPARTAMENTO DE ARQUIVO PÚBLICO DO ESTADO DO PARANÁ, 1808).

Compete salientar que dentre as mais expressivas oportunidades angariadas por açorianos em Morretes e Paranaguá, nos séculos XVIII e XIX, estavam o ingresso célere no mercado matrimonial e o alcance da posição de comerciante autônomo ou proprietário rural. Tais conquistas, entretanto, representavam também os limites das oportunidades por eles auferidas.

Após duas décadas da abertura de seu processo de dispensa matrimonial, João Ferreira de Oliveira permanecia acomodado na posição de comerciante varejista em Morretes. Em 1808, ele foi citado na Lista Nominativa da vila de Antonina, sob a jurisdição da qual estava a povoação de Morretes, como tenente de Milícias que exercia a ocupação de comerciante de secos e molhados, e também praticava a agricultura de subsistência. No mencionado ano, João Ferreira possuía uma escravaria composta por doze indivíduos (7 escravos do sexo masculino e 5 do sexo feminino), que tinham idades entre 2 e 52 anos (DEPARTAMENTO DE ARQUIVO PÚBLICO DO ESTADO DO PARANÁ, 1808).

Há que destacar, pois, três elementos do percurso de João Ferreira naquela povoação. Um elemento é a estabilidade de sua atuação profissional. Nota-se, pois, que ele não experimentou reveses econômicos que demandassem a mudança de ocupação profissional ou a realização de migração interna. Havia, pois, um aspecto rotineiro na trajetória daquele açoriano no litoral do extremo sul paulista.

O segundo elemento foi a sua ascensão na Companhia de Ordenanças. Tratou-se de uma ascensão análoga àquela experimentada por seu irmão Antônio Ferreira na segunda metade do século XVIII, visto que ambos alcançaram a patente de Tenente.

O terceiro elemento reside no fato de que João Ferreira se tornou o senhor de uma escravaria cujo contingente era superior ao contingente médio das escravarias do litoral do atual Paraná. Em 1808, havia 837 escravos em Antonina (420 homens e 417 mulheres). Esses escravos estavam distribuídos em 124 domicílios, em um universo de 615 residências. Portanto, a composição média das 
Imigração, relações familiares e atividades econômicas no Brasil...

escravarias em Antonina, em 1808, era de 6,8 cativos por domicílio (DEPARTAMENTO DE ARQUIVO PÚBLICO DO ESTADO DO PARANÁ, 1808).

João Ferreira faleceu em 1809. Nesse contexto, uma de suas filhas, Maria, estava casada desde 1804 com Antônio Vieira dos Santos, natural da cidade portuguesa do Porto. $\mathrm{Na}$ época, esse português atuava como comerciante varejista em Paranaguá (SANTOS, 1827, p. 6). Em 1809, outro português, Antônio José de Araújo (1791-1851), passou a integrar a família dos Ferreira de Oliveira. Ele casou-se com Domitila, filha de João Ferreira (SANTOS, 1827, p. 12).

Vieira dos Santos e Antônio de Araújo principiaram a enraizar-se na sociedade de Paranaguá na condição de caixeiros de um irmão de João Ferreira, Francisco Ferreira de Oliveira. Assim, em uma área litorânea do extremo sul da Capitania de São Paulo, no início do século XIX, a proximidade entre jovens caixeiros portugueses com comerciantes açorianos ali radicados desde a segunda metade do século XVIII permitiu aos primeiros o ingresso célere no mercado matrimonial da localidade.

De fato, há tempos a historiografia salientou que, no contexto do Brasil colonial, tornar-se empregado de um compatriota permitia ao imigrante, por vezes, assumir os negócios de seu antigo patrão e contrair matrimônio com uma de suas descendentes (BOXER, 1969).

Vieira dos Santos e Antônio de Araújo não herdaram os negócios de seu antigo empregador. Porém, após a morte de João Ferreira, eles se tornaram os condutores das atividades econômicas dos Ferreira de Oliveira em Morretes. Em suma, as formas de solidariedade entre um imigrante português e a família açoriana que o acolhia não se esgotavam no momento da morte do patriarca desta família. A esse respeito, atente-se ao caso de Antônio Vieira dos Santos. Ele fora um comerciante varejista que vivenciou, em Paranaguá, a falência de seus negócios. Para se reabilitar na vida mercantil, fixou residência na então freguesia de Morretes, em 1814 (SANTOS, 1827, p. 20).

Por meio do auxílio econômico da viúva de João Ferreira e do compatriota Antônio de Araújo, ele se fixou naquela localidade como comerciante varejista e negociante de erva-mate. Esse auxílio econômico permitiu-lhe recomeçar na vida mercantil em outra 
sociedade litorânea. Contudo, tal ajuda tornou-o dependente, ao longo da primeira metade do século XIX, dos subsídios pecuniários de membros da família Ferreira de Oliveira.

Nesse particular, cabe destacar que, quando do falecimento de João Ferreira, em 1809, Vieira dos Santos lhe devia a quantia de 1:408\$804 conto de réis. Esse comerciante também tinha débitos com a sua sogra. Em 1824, ano da morte de Ana Gonçalves, Vieira dos Santos lhe devia o valor de $134 \$ 155$ réis (SANTOS, 1827, p. 245-246).

Em síntese, cabe destacar que, no âmbito das sociedades de Morretes e Paranaguá, os Ferreira de Oliveira eram inclinados a absorver imigrantes recém-chegados. Essa absorção decorria tanto do fato de proporcionarem àqueles imigrantes um treinamento na vida mercantil quanto da concessão da faculdade de envolver esses adventícios em esquemas matrimoniais.

Ao mesmo tempo, trata-se de salientar que a concessão de empréstimos consistiu em uma forma de os Ferreira de Oliveira viabilizarem o desenvolvimento das atividades econômicas do citado Vieira dos Santos. Mais precisamente, o estabelecimento de relações familiares com os Ferreira de Oliveira garantiu àquele indivíduo as condições para se reabilitar na vida comercial após ter vivenciado uma falência no início dos anos 1810. A captação de empréstimos junto a membros da comunidade étnica portuguesa de Paranaguá foi também crucial para a manutenção das atividades comerciais de Vieira dos Santos (GOMES, 2012).

\section{Administração municipal, comércio e treinamento de caixeiros na vila de Paranaguá: o caso de Francisco Ferreira de Oliveira}

O estudo sobre o processo de inserção de um irmão de João Ferreira de Oliveira, o açoriano Francisco Ferreira de Oliveira, na vila de Paranaguá permite a sustentação de quatro argumentos. Primeiro, afirma-se que o exercício de uma ocupação da vida mercantil era operacional para um ingresso mais célere nos esquemas matrimoniais que funcionavam naquele município. 
Imigração, relações familiares e atividades econômicas no Brasil...

Para a demonstração desse argumento, é procedida uma comparação dos perfis sociais dos principais interlocutores de Francisco Ferreira na vila de Paranaguá nos anos 1780 . Nesse particular, é destacado que os imigrantes que se dedicavam aos trabalhos marítimos e aos trabalhos rurais experimentaram, em Paranaguá, maiores restrições para o ingresso no mercado matrimonial.

O segundo argumento comporta a afirmação de que Francisco Ferreira teve a sua trajetória marcada pela constituição de vínculos sociais e familiares para além da vila de Paranaguá. Dessa forma, trata-se de destacar os aspectos e os limites das conexões familiares desse imigrante na sociedade receptora. O principal limite é de que tais conexões eram circunscritas a uma região litorânea.

$\mathrm{O}$ terceiro argumento salienta que um indício da mobilidade social ascendente de Francisco Ferreira foi a sua admissão a esferas da vida administrativa de Paranaguá. Mais precisamente, o seu ingresso na Câmara Municipal de Paranaguá, na qualidade de vereador, evidencia a sua incorporação à elite local.

O quarto argumento comporta a afirmação de que Francisco Ferreira estava envolvido em uma dinâmica de arregimentação e treinamento de caixeiros portugueses. O oferecimento de um treinamento na vida mercantil a jovens recém-chegados era uma das formas de dominação exercidas por Francisco Ferreira na sociedade receptora. Nesse estágio do artigo é corroborado o argumento de que a acomodação nessa posição de dependência a outro imigrante lusófono era a etapa inicial da conquista, pelo jovem imigrante, de oportunidades tais como o ingresso em esquemas matrimoniais e o alcance da condição de comerciante autônomo.

O processo de dispensa matrimonial de Francisco Ferreira de Oliveira foi aberto no dia 19 de agosto de 1789 pelo vigário de Paranaguá, Pedro Domingues Paes Leme. Natural da Ilha do Pico, aquele imigrante açoriano estava, à época, na idade de 20 anos e residia na vila de Paranaguá há três anos. Ele o seu irmão João Ferreira seguiram trajetos distintos no litoral do atual Paraná. Ao passo que João Ferreira radicou-se em uma povoação do interior da vila de Paranaguá, Francisco Ferreira fixou residência na área mais urbanizada desse município.

A permanência nesse núcleo, todavia, não o impediu de estabelecer conexões familiares com membros da freguesia de Antonina, 
que na época pertencia à jurisdição de Paranaguá e foi elevada à categoria de município em 1797. Assim, o processo de dispensa matrimonial de Francisco Ferreira foi aberto para que ele pudesse atestar que atendia aos requisitos necessários para casar-se com Eufrosina da Silva Freire, residente em Antonina (Processo de Dispensa Matrimonial de João Ferreira de Oliveira, 1789, p. 1). Trata-se de uma localidade distante cerca de cinquenta quilômetros do núcleo urbano do município de Paranaguá.

A mobilidade e o estreitamento de conexões familiares em áreas do interior do município de Paranaguá foram, pois, aspectos peculiares ao princípio do trajeto de Francisco Ferreira no extremo sul do litoral paulista. Essa mobilidade foi mais limitada em relação àquela efetuada por imigrantes que também contraíram núpcias em Paranaguá nas décadas de 1780 e 1790 . Houve, pois, imigrantes que constituíram vínculos sociais na área correspondente ao primeiro planalto do atual Paraná. ${ }^{4}$

Outro aspecto do trajeto de Francisco Ferreira consistiu na manutenção de interações com imigrantes que, no fim dos anos 1780, estavam acomodados em uma posição mais modesta na hierarquia social da vila de Paranaguá. Esses imigrantes eram distinguidos pelo afastamento em relação aos esquemas matrimoniais em vigor naquela localidade. A atenção aos perfis sociais dos interlocutores de Francisco Ferreira permite corroborar o argumento de que havia um sensível vínculo entre ocupação profissional e oportunidades de estabelecimentos de vínculos familiares naquela sociedade receptora.

A primeira testemunha desse processo de dispensa matrimonial era José Álvares de Sousa, natural da cidade portuguesa do Porto. Nesse contexto, ele estava na idade de 26 anos, era solteiro e atuava como marujo. Ele afirmou que conhecera Francisco Ferreira em Portugal, na época em que se transferiram para o Brasil (Processo de Dispensa Matrimonial de João Ferreira de Oliveira, 1789, p. 2).

Conforme o depoimento de José Álvares, Francisco Ferreira matinha interações com diversos patrícios no litoral sul paulista. Esses patrícios estavam informados sobre as origens sociais e o processo de estabelecimento desse açoriano no Brasil. Álvares afirmou que estava ciente de que Ferreira "era solteiro, livre e desimpedido porque tem conversado com patrícios do justificante que o conhecem e assim o tem ouvido o que tudo sabia ele testemunha por ter 
Imigração, relações familiares e atividades econômicas no Brasil...

ouvido como afirma” (Processo de Dispensa Matrimonial de João Ferreira de Oliveira, 1789, p. 2).

Verifica-se que, no contexto do litoral sul paulista, no fim do século XVIII, os imigrantes açorianos e reinóis mantinham-se próximos. Nesse âmbito, trata-se de destacar que essa proximidade era também condicionada por fatores econômicos. Os imigrantes que exerciam profissões tais como a de caixeiro, comerciante varejista e marujo, no âmbito da vila de Paranaguá, eram os imigrantes que mantinham entre si os mais consistentes vínculos. Porém, existiam marcantes diferenças entre esses interlocutores. Uma das principais diferenças decorria da maior ou menor capacidade de ser absorvido ao mercado matrimonial da sociedade receptora.

Aos imigrantes que se dedicavam ao comércio, era facultada uma integração mais rápida àquele mercado. Desse modo, cabe destacar que, a despeito do fato de ingressarem juntos na sociedade de Paranaguá, Francisco Ferreira e José Álvares se diferenciavam entre si quanto à capacidade de constituição de vínculos familiares. Ao contrário do caso de Francisco Ferreira, José Álvares, no fim dos anos 1780, estava afastado dos esquemas matrimoniais vigentes naquela vila.

Nesse contexto, a restrição para o ingresso em esquemas matrimoniais da vila de Paranaguá não era imposta apenas aos marujos. Os indivíduos que estavam submetidos ao comando de um patrão não pertenciam ao rol de jovens imigrantes inseridos no mercado matrimonial. A segunda testemunha do processo de dispensa matrimonial de Francisco Ferreira trabalhava como feitor. Há de aventar, pois, a hipótese que ele era empregado de um dos proprietários da vila. Esse feitor era o português José de Oliveira Marques. Em 1789, ele estava na idade de 28 anos e permanecia solteiro (Processo de Dispensa Matrimonial de João Ferreira de Oliveira, 1789, p. 3).

A terceira testemunha desse processo de dispensa era Pedro Lourenço, português originário do Arcebispado de Braga. Ele era marujo, estava na idade de 23 anos e permanecia solteiro.

Em resumo, a principal diferença entre Francisco Ferreira e os seus referidos interlocutores reside no fato de que quando se transferiu para o litoral sul paulista, ele já possuía o apoio social e 
familiar necessário para se consolidar como comerciante autônomo. Note-se, pois, que o seu irmão Antônio de Oliveira atuava como comerciante em Paranaguá ao menos desde o início dos anos 1780. Conforme demonstrado na seção seguinte deste artigo, o destino de Francisco Oliveira em Paranaguá, nas primeiras três décadas do século XIX, consistiu em conservar a sua posição de comerciante autônomo e assegurar a prerrogativa de participar da vida administrativa daquele município.

Em 1808, Francisco Ferreira de Oliveira foi referido na Lista Nominativa de Habitantes de Paranaguá como negociante e Capitão das Ordenanças. O exercício desse posto de comando lhe garantiu, naquele ano, rendimentos que totalizaram o valor de 400 mil réis (DEPARTAMENTO DE ARQUIVO PÚBLICO DO ESTADO DO PARANÁ, 1808). Nessa época, ele possuía uma escravaria formada apenas por quatro cativos ( 3 do sexo feminino e 1 do sexo masculino), que tinham idades entre 12 e 41 anos.

Nessa época, uma forma de exercício de dominação social por Francisco Ferreira decorria da qualidade de patrão de caixeiros, dentre os quais se encontravam jovens de origem portuguesa. Ao rememorar o período em que findou no período de sua atuação como caixeiro de Francisco Ferreira, Vieira dos Santos afirmou:

Em 10 de Fevereiro de 1805 Domingo veio meu Mano João Vieira dos Santos para minha companhia de que lhe dei interesse no meu Armazém tendo para isso falado com seu Amo o Capitão Ricardo de Souza Pinto para ele sair de sua Casa. Em 15 de Fevereiro de 1805 Sexta feira fiquei desde este dia em diante Senhor Absoluto de mim (SANTOS, 1827, p. 6).

No excerto supracitado, nota-se que não era incomum o emprego do qualificativo de amo para designar um patrão. Ao descrever o momento do fím da atuação de um de seus irmãos como caixeiro de Paranaguá, Vieira dos Santos salientou esse caráter de dependência pessoal do empregado para com o patrão. 
Imigração, relações familiares e atividades econômicas no Brasil...

Essa dependência, em determinadas circunstâncias, era também de natureza econômica. A relação verticalizada entre o empregado e o patrão não se dissolvia no momento em que o primeiro assumia a condição de comerciante autônomo. Francisco Ferreira, portanto, manteve-se em uma posição de dominação econômica em relação ao seu antigo caixeiro Antônio Vieira dos Santos. A esse respeito, cumpre destacar que, em 1822, ano do falecimento de Francisco Ferreira, Vieira dos Santos devia a este açoriano a quantia de $455 \$ 625$ réis (SANTOS, 1827, p. 245).

Portanto, um dos aspectos da atuação de Francisco Ferreira na sociedade de Paranaguá era o seu envolvimento no mercado de crédito. $\mathrm{O}$ pertencimento ao grupo de controladores locais desse mercado permitia reunir em torno de si um contingente de indivíduos que, de forma reiterada, demandavam a concessão de empréstimos. Na vila de Paranaguá, na primeira metade do século XIX, houve portugueses que consolidaram o seu poder econômico ao se tornarem fornecedores de crédito.

Desse modo, imigrantes menos abastados, tais como Vieira dos Santos, faziam parte do séquito de dependentes de seus compatriotas. No início dos anos 1820, por exemplo, esse português devia a Manuel Antônio Pereira (1782-1857) a quantia de 2:253\$262 contos de réis, bem como possuía junto a Manuel Francisco Correia (1776-1864) um débito de 1:570\$107 conto de réis (SANTOS, 1827, p. 245). Pereira e Correia eram negociantes originários de Portugal.

Cabe destacar, por fim, que em 1820 o açoriano Francisco Ferreira era vereador em Paranaguá. Tal posição qualificou-o a participar de tomadas de decisão a respeito de assuntos que interessavam, por exemplo, o grupo profissional de qual fazia parte. De todo o modo, trata-se de ressaltar que a presença de açorianos na Câmara de Paranaguá era ocasional. Nas primeiras três décadas do século XIX, houve a inserção mais frequente de reinóis nessa instituição. ${ }^{5}$

Um dos assuntos de interesse dos negociantes de Paranaguá era a realização de obras na Estrada de Curitiba, que fazia a ligação entre Morretes e a vila de Curitiba. No referido ano, o rei D. João VI autorizou a feitura dos reparos (SANTOS, 1950, p. 88). A capacidade de obter uma eleição para a Câmara Municipal e, no exercício do mandato, buscar a viabilização de demandas setoriais foi elemento intrínseco aos anos finais da trajetória daquele imigrante açoriano. 


\section{Imigração, agricultura e escravidão na vila de Paranaguá: o caso de José Soares}

O estudo sobre a inserção e percurso de José Soares na vila de Paranaguá permite a feitura de quatro constatações. Primeiro, constata-se que o apoio de familiares radicados na sociedade receptora, no início dos anos 1780, era crucial para o enraizamento de açorianos.

Segundo, é afirmado que a abertura de processo de dispensa matrimonial era também solicitada por imigrantes solteiros. Tais imigrantes buscavam uma certificação oficial de que estavam desimpedidos para contrair matrimônio. Em resumo, cabe salientar que a posse desse certificado era encarada por imigrantes tais como João Soares como elemento estratégico para a inserção no mercado matrimonial da Paranaguá setecentista.

Terceiro, demonstra-se que não era incomum ocorrer uma mudança de ocupação profissional por açorianos. Existiram, na vila de Paranaguá setecentista, imigrantes cujos trajetos foram mais acidentados em relação aos trajetos de seus compatriotas.

Quarto, cumpre reconhecer que o exercício de atividades econômicas rurais era uma ocupação adotada por açorianos radicados naquela localidade em fins do século XVIII.

Quinto, é evidenciado que a formação de uma escravaria composta por um número superior ao número médio de cativos das escravarias da vila era um elemento basilar do poder econômico de açorianos como João Ferreira e José Soares, no limiar do século XIX.

O processo de dispensa matrimonial de José Soares foi aberto no dia 7 de janeiro de 1780 pelo vigário interino Francisco de Meira. Soares era natural da Ilha de São Miguel e estava na idade 33 anos. Ele migrara para o Brasil por volta do ano de 1777 (Processo de Dispensa Matrimonial de João Ferreira de Oliveira, 1780, p. 1).

Nessa oportunidade, João Soares não possuía uma noiva. Antes, ele ambicionava obter o certificado de dispensa matrimonial para demonstrar, na sociedade de Paranaguá, que não possuía qualquer impedimento para contrair núpcias. Dessa maneira, uma das etapas iniciais da estratégia de enraizamento social desse açoriano era consolidar e ampliar seus vínculos sociais no município receptor por meio do casamento. Realizado na segunda etapa desta seção, o 
Imigração, relações familiares e atividades econômicas no Brasil...

estudo da Lista Nominativa de Paranaguá do ano de 1808 possibilita asseverar que ele concretizou o objetivo de casar.

De outra parte, o processo de dispensa matrimonial de João Soares evidencia que a razão pela qual migrou para o Brasil decorria da dificuldade de exercer uma ocupação na terra de origem. Diante dessa dificuldade, foi recebido na vila de Paranaguá por seu pai, o marceneiro Antônio Fernandes. De fato, não há informações na dispensa de que o patriarca incumbiu-se da tarefa de ministrar ao filho os conhecimentos de um ofício artesanal.

De todo o modo, a análise do depoimento que esse marceneiro prestou no processo de dispensa matrimonial de seu filho evidencia que ele, Antônio Fernandes, incumbiu-se da tarefa de viabilizar a inserção de seu filho na vida econômica de Paranaguá. No entendimento desse patriarca, uma forma adequada de propiciar ao seu filho a obtenção de oportunidades na sociedade receptora era fazê-lo adentrar de forma célere aos esquemas matrimoniais que ali existiam.

O processo de dispensa de José Soares possui três testemunhas. Uma testemunha é o pai do justificante, o citado marceneiro Antônio Soares, que era casado e estava na idade de 59 anos. Nesse depoimento, o marceneiro Soares salientou que o seu propósito ao promover a vinda de seu filho para o Brasil era "arrumá-lo de algum modo e casá-lo” (Processo de Dispensa Matrimonial de João Ferreira de Oliveira, 1780, p. 2). Na ocasião, José Soares ainda não possuía uma noiva. A abertura do processo de dispensa era, pois, a etapa inicial para ele obter um atestado da Igreja Católica de que estava desimpedido para contrair núpcias.

A segunda testemunha do processo de dispensa era Manoel José de Faria, natural da Ilha Terceira dos Açores. Em 1780, ele estava na idade de 22 anos, era solteiro e atuava como comerciante varejista. A terceira testemunha, por fim, era o negociante Antônio de Oliveira Pedroso, natural de Paranaguá. Nessa época, ele estava na idade de 44 anos.

A análise do caso de Joao Soares permite salientar uma situação na qual havia ocasiões nas quais a migração de açorianos para o Brasil não ocorria no período da menoridade ou princípio da juventude. Antes, tal migração era decorrente da falta de oportunidades 
econômicas enfrentadas por adultos naturais do Arquipélago dos Açores. O destino de José Soares, porém, não consistiu em seguir o ofício paterno. Ele inclinou-se para o desenvolvimento de atividades agrárias.

Conforme a Lista Nominativa de Paranaguá, em 1808 José Soares residia em uma área rural de Paranaguá denominada de Bairro do Saco do Tambarutaca. Nessa época, Soares estava na faixa dos 60 anos de idade, era viúvo e residia junto a cinco filhos (três do sexo feminino e dois do sexo masculino), com idades entre 10 e 23 anos. Em seu domicílio foram contabilizados nove escravos (cinco do sexo feminino e quatro do sexo masculino), com idades entre 12 e 46 anos. José Soares foi citado na lista como praticante de agricultura de subsistência (DEPARTAMENTO DE ARQUIVO PÚBLICO DO ESTADO DO PARANÁ, 1808).

De todo o modo, ele possuía uma escravaria cujo contingente era superior à média do contingente das escravarias da aludida vila. Em 1808, em Paranaguá, havia 1132 escravos (609 do sexo feminino e 523 do sexo masculino) distribuídos em 197 domicílios. Assim, a média de escravos era de 5,75 cativos por domicílio. Em resumo, Soares amealhou seu cabedal, do qual faziam parte os cativos, por meio da atuação na vida agrícola do município de Paranaguá.

\section{Considerações finais}

Os resultados da investigação efetuada no decorrer deste artigo permitem a feitura de duas afirmações. Primeiro, verificou-se que, no fím do século XVIII, no contexto da vila de Paranaguá e da povoação de Morretes, o apoio de familiares foi crucial para a inserção de açorianos na sociedade receptora. Havia, contudo, distinções quanto às formas de concessão desse apoio. Existiram imigrantes, tais como Francisco e João Ferreira de Oliveira, que foram acolhidos por parentes para serem treinados na vida mercantil na época da menoridade e início da juventude.

De outra parte, havia imigrantes adultos, tais como José Soares, que recebiam o apoio para encontrarem uma ocupação no sul do litoral paulista em virtude de reveses econômicos e profissionais 
Imigração, relações familiares e atividades econômicas no Brasil...

experimentados na terra de origem. Assim, a vila de Paranaguá setecentista era tanto um espaço para o início da vida profissional de açorianos ligados ao comércio quanto local para a reabilitação econômica de imigrantes lusófonos. Nesse quadro, foi demonstrado que era operacional aos imigrantes portugueses permanecerem próximos aos comerciantes açorianos estabelecidos em Morretes e Paranaguá. Essa proximidade era uma estratégia para a obtenção de oportunidades econômicas e formação de conexões familiares.

Segundo, a formação de uma escravaria, a conquista de posições na Companhia de Ordenanças e de cargos administrativos eram aspectos, no início do século XIX, da consistência do enraizamento social de açorianos nas referidas localidades. Ao mesmo tempo, a atuação na agricultura não era rejeitada por tais imigrantes - a atenção aos casos de João Ferreira de Oliveira e José Soares permitiu demonstrar esta assertiva.

\section{IMMIGRATION, FAMILY RELATIONSHIPS AND ECONOMIC ACTIVITIES IN SOUTHERN BRAZIL: FORMS OF ENTRY AND SOCIAL MOBILITY OF THREE AZOREANS IN COASTAL AREAS OF CAPTAINCY OF SÃO PAULO (MORRETES AND PARANA- GUÁ, 1780-1820)}

Abstract: The present study includes an investigation into the rooting and social mobility process of three Azorean immigrants in two coastal areas of Captaincy of São Paulo - the district of Morretes and municipality of Paranaguá - between the years of 1780 and 1820 . The main purpose of this article is to produce knowledge about the nature of social and economic opportunities that Azoreans took part in the migratory flow to coastal areas of Southern Brazil in the second half of the 18th century. In this context, the central argument of this investigation states that, in the context of the 1780s, Azorean immigration to the southern tip of the São Paulo captaincy was sometimes a family project. In this way, the existence of forms of solidarity between members of different generations between Azorean and Portuguese immigrants is pointed out. In this context, two sources are used. Initially, matrimonial dispensing processes are studied, which contain information about the beginning of the social roots of the three Azoreans listed here. Two nominative lists of inhabitants are also studied, which makes it possible to know the fate of these immigrants in the early nineteenth century.

Keywords: Azoreans. Immigration. Local elites. Southern Brazil. 


\section{Notas}

${ }^{1}$ Esse arquivo está situado na Avenida Nazaré, n. 993, bairro do Ipiranga, cidade de São Paulo.

${ }^{2}$ Esse volume de memórias está sob a guarda do Círculo de Estudos Bandeirantes (Curitiba, Rua XV de Novembro, 1050). A transcrição integral dos textos memorialísticos de Antônio Vieira dos Santos foi publicada em 2014 (CAVAZZANI; GOMES, 2014).

${ }^{3}$ Este processo integra a Série de Dispensas e Processos Matrimoniais (1780-1789) disponível para consulta no Arquivo Metropolitano Dom Leopoldo e Silva, Mitra Diocesana de São Paulo: ARQUIVO METROPOLITANO DOM LEOPOLDO E SILVA, MITRA DIOCESANA DE SÃO PAULO. Série de Dispensas e Processos Matrimoniais (1780-1789). Documentação manuscrita produzida por agentes da Vara Eclesiástica do município de Paranaguá.

${ }^{4}$ Por meio da consulta aos processos de dispensas matrimoniais abertos em Paraná nas décadas de 1780 e 1790, verifica-se que os portugueses José Fernandes Pancada e Tomé José Monteiro Braga se fixaram no município de Paranaguá e mantinham conexões sociais na vila de Curitiba. O português João Crisóstomo, por seu turno, migrara de Paranaguá para Curitiba. (ARQUIVO METROPOLITANO DOM LEOPOLDO E SILVA, 1781-1793).

${ }^{5}$ Em 1820, Francisco Ferreira de Oliveira era o único imigrante pertencente à Câmara de Paranaguá. Os demais vereadores eram Bento Antônio da Costa (filho do imigrante português Manuel Antônio da Costa), Antônio José da Costa e Joaquim Antônio Guimarães (filho do imigrante português Manuel Gonçalves Guimarães). Trava-se, pois, de uma Câmara composta majoritariamente por brasileiros, dentre os quais havia filhos de imigrantes provenientes do Reino de Portugal. Anteriormente, os irmãos portugueses Antônio e João Vieira dos Santos haviam exercido mandatos naquela instituição. Ao passo que João dos Santos fora vereador em 1811, Antônio dos Santos ali atuara como procurador em 1812. Em 1829, por fim, estavam a exercer mandatos na Câmara de Paranaguá os citados portugueses Manuel Antônio Pereira e Manuel Francisco Correia (SANTOS, 2001, p. 238; p. 390).

\section{Referências}

ARQUIVO METROPOLITANO DOM LEOPOLDO E SILVA, MITRA DIOCESANA DE SÃO PAULO. Série de Dispensas e Processos Matrimoniais (17801789). Documentação manuscrita produzida por agentes da Vara Eclesiástica do município de Paranaguá.

Anos 90, Porto Alegre, v. 24, n. 46, p. xx-xx, dez. 2017 
Imigração, relações familiares e atividades econômicas no Brasil...

BALHANA, Altiva. Santa Felicidade. Uma paróquia Vêneta no Brasil. Curitiba: Fundação Cultural, 1978.

BIDEAU, Alain; NADALIN, Sérgio Odilon. Une communauté allemande au Brésil: de l'immigration aux contacts culturels, XIXe-XXe siècle. Paris: Ined, 2011. BLUME, Wellingotn Augusto; WITT, Marcos Antônio. Organização social e mobilidade espacial: estudo sobre imigrantes alemães e descendentes no Brasil e Argentina. Ágora, Santa Cruz do Sul, v. 16, n. 1, p. 97-111.

BORREGO, Maria. A teia mercantil: negócios e poderes em São Paulo colonial (1711-1765). São Paulo: Alameda, 2010.

BOXER, Charles. A Idade do Ouro do Brasil. São Paulo: Companhia Editora Nacional, 1969.

BRAGA, Nilza Lícia Xavier Silveira. Entre negócios e vassalagem na Corte joanina: a trajetória do homem de negócio, o comendador da Ordem de Cristo e deputado da Real Junt ode Comércio Eilas Antonio Lopes (c.1770-1815). Dissertação (Mestrado em História)-Universidade Federal Fluminense, Niterói, 2014. CARVALHO NETO, João Baptista de. Floriano Essenfelder: a trajetória de um empresário. Dissertação (Mestrado em História)-Universidade Federal do Paraná, Curitiba, 1991.

CAVAZZANI, André Luiz Moscaleski. Tendo o sol por testemunha: população portuguesa na Baía de Paranaguá (c.1750-1830). Tese (Doutorado em História Social)-Universidade de São Paulo, São Paulo, 2013.

CAVAZZANI, André Luiz Moscaleski; GOMES, Sandro Aramis Richter. Antônio Vieira dos Santos: reminiscências e outros escritos. Curitiba: Editora da Universidade Federal do Paraná, 2014.

DEPARTAMENTO DE ARQUIVO PÚBLICO DO ESTADO DO PARANÁ. Lista Nominativa das Vilas de Antonina e Paranaguá. Documentação manuscrita produzida por agentes da Companhia de Ordenanças dos municípios de Antonina e Paranaguá. 1808.

GOLDSCHMIDT, Eliana. Casamentos mistos: liberdade e escravidão na São Paulo colonial. São Paulo: Annablume/Fapesp, 2004.

GOMES, Sandro Aramis Richter. Descentralização e pragmatismo: condições sociais de produção das memórias históricas de Antônio Vieira dos Santos. Dissertação (Mestrado em História)-Universidade Federal do Paraná, Curitiba, 2012. GORENSTEIN, Riva; MARTINHO, Lenira. Negociantes e Caixeiros na Sociedade da Independência. Rio de Janeiro: Secretaria Municipal da Cultura, 1993. 
HAMEISTER, Martha Daisson. Para dar calor à nova povoação: estratégias sociais e familiares a partir dos registros batismais da Vila do Rio Grande (c.1748-1763). Tese (Doutorado em História Social)-Universidade Federal do Rio de Janeiro, Rio de Janeiro, 2006.

HELFENSTEIN, Janaína Cristiane da Silva. Entre a vida comunitária e a vida conjugal: a composição das famílias luteranas de Imbituva, Paraná (1943-1959). Dissertação (Mestrado em História)-Universidade Federal do Paraná, Curitiba, 2014.

LEANDRO, José Augusto. Gentes do grande mar redondo: riqueza e pobreza na Comarca de Paranaguá (1850-1888). Tese (Doutorado em História)-Universidade Federal de Santa Catarina, Florianópolis, 2003.

MACHADO, Cacilda. De uma família imigrante: sociabilidades e laços de parentesco. Curitiba: Aos Quatro Ventos, 1998.

MARQUES, Rachel dos Santos. Por cima da carne seca: hierarquia e estratégias sociais no Rio Grande do Sul (c.1750-1820). Curitiba: Universidade Federal do Paraná, 2012.

NADALIN, Sérgio Odilon. Une paroisse germanique au Brésil: la communauté évangélique luthérienne à Curitiba entre 1866 et 1969. Tese (Doutorado em História e Geografia das Populações)-École des Hautes Études en Sciences Sociales, Paris, 1978.

PIAZZA, Walter. A epopeia açórico-madeirense: 1747-1756. Floranópolis: UFSC/ Lunardelli, 1997.

. A Paróquia do Rio Grande de São Pedro. Estudo de História Demográfica, 1737-1850. Rio Grande: FURG, 1987.

QUEIROZ, Maria Luiza Bertulini. Paróquia de São Pedro do Rio Grande: estudo de história demográfica (1737-1850). Tese (Doutorado em História)-Universidade Federal do Paraná, Curitiba, 1992.

A vila do Rio Grande de São Pedro: 1737-1822. Rio Grande: FURG, 1987.

RANZI, Serlei Fischer. Alemães católicos: um estudo comparativo de famílias em Curitiba (1850-1919). Tese (Doutorado em História)-Universidade Federal do Paraná, Curitiba, 1996.

ROCHE, Jean. A colonização alemã e o Rio Grande do Sul. 2 v. Porto Alegre: Globo, 1969.

SANTOS, Antônio Vieira dos. Breve resumo das memórias mais notáveis acontecidas desde 1797 até 1827. Manuscrito. 
Imigração, relações familiares e atividades econômicas no Brasil...

. Memória Histórica da Vila de Morretes. [1851]. Curitiba: Edição do Museu Paranaense, 1950.

. Memória Histórica de Paranaguá e seu município. [1850]. v. 1. Curitiba: Vicentina, 2001.

SCARPIM, Fábio Augusto. Bens simbólicos em laços de pertencimento: família, religiosidade e identidade étnica nas práticas de transmissão de nomes de batismo em um grupo de imigrantes italianos (Campo Largo/PR, 1878-1937). Dissertação (Mestrado em História)-Universidade Federal do Paraná, Curitiba, 2010.

SCOTT, Ana Volpi (Org.). Gentes das Ilhas: trajetórias transatlânticas dos Açores ao Rio Grande de São Pedro entre as décadas de 1740 e 1790. São Leopoldo: Oikos, 2014.

SEYFERTH, Giralda. Etnicidade, política e ascensão social: um exemplo teuto-brasileiro. Mana, Rio de Janeiro, v. 5, n. 2, out. 1999, p. 61-88.

STORMOWSKI, Márcia. Crescimento e econômico e desigualdade social. Dissertação (Mestrado em História)-Universidade Federal do Rio Grande do Sul, Porto Alegre, 2014.

TÖNNIES, Ferdinand. Para ler Ferdinand Tönnies. Organização Orlando de Miranda. São Paulo: Editora da Unesp, 1995.

VENDRAME, Maíra Inês. O poder na aldeia: redes sociais, honra familiar e práticas de justiça entre os camponeses italianos (Brasil-Itália). São Leopoldo: Oikos, 2016.

WACHOWICZ, Ruy Cristovam. Abranches: paróquia da imigração polonesa. Dissertação (Mestrado em História)-Universidade Federal do Paraná, Curitiba, 1974.

Recebido em: 06/11/2016

Aprovado em: 10/04/2017 